Vytenis Miliušas*

The Strategic Communication Department of the Lithuanian Armed Forces

Viktor Denisenko ${ }^{* *}$

The General Jonas Žemaitis Military Academy of Lithuania

\title{
Strategic Communication of NATO Enhanced Forward Presence Battle Group in Lithuania by Assessment of the Parties Involved in the Process
}

\begin{abstract}
The article presents the study on strategic communication of NATO Enhanced Forward Presence Battle Group in Lithuania and assessment of the effectiveness thereof by the representatives of the parties involved in the process. The academic research of this issue has been scarce, especially in the case of focussing on the aspects of strategic communication, despite the fact that the battle groups have been deployed to the Baltic States and Poland in early 2017. Assessments by the representatives of the parties involved in the process indicate certain trends in communications, enable answering the question regarding the direction to be taken in respect of the communications of the battle group and what communication goals are being implemented.
\end{abstract}

\section{Introduction}

NATO Enhanced Forward Presence was deployed to the Baltic States and Poland more than two years ago in response to Russia's aggression against Ukraine. This step was taken as means of military deterrence against Russia. However, the question remains as to what place is taken by NATO's strategic communication in deterrence actions and how it is implemented by using NATO Enhanced Forward Presence Battle Group in Lithuania.

The issue of military deterrence of Russia has once again become relevant as a result of the Kremlin's actions. According to George Weigel, Russia

\footnotetext{
${ }^{*}$ Cpt. Vytenis Miliušas is an Officer of the Strategic Communication Department of the Lithuanian Armed Forces. Address: Šv. Ignoto 8, LT-01120, Vilnius, Lithuania; tel.: +370 527850 30,

e-mail: vytenis.miliusas@gmail.com

"Dr. Viktor Denisenko is an Assoc. Professor of the General Jonas Žemaitis Military Academy

of Lithuania. Address: Šilo 5A, LT-10322 Vilnius, Lithuania; tel.: +370 5212 6313;

e-mail: viktor.denisenko@lka.lt
}

https://doi.org/10.47459/lasr.2020.18.4

(C) Vytenis Miliušas, Viktor Denisenko, 2020

(C) Military Academy of Lithuania, 2020 
under Vladimir Putin's rule is engaged in a revanchist policy ${ }^{1}$. The Russia-Georgia War in 2008 as well as the subsequent annexation of Crimea in 2014 and the war that broke out in East Ukraine served as an ultimate demonstration of Russia's strategic goals thus confirming that the previous conflicts were no coincidence. The conflict in East Ukraine is one of the extreme illustrations of Russia's new policy based on the demonstration of military power ${ }^{2}$.

NATO Alliance was forced to respond to the aforementioned actions taken by the Kremlin. The Eastern Flank of the North Atlantic Treaty Organization was being strengthened first. The leaders unanimously decided to deploy NATO Enhanced Forward Presence Battle Groups to Estonia, Latvia, Lithuania, and Poland as well as Tailored Forward Presence to Rumania and Bulgaria during the NATO Summit held in Warsaw in the summer of 2016. This decision was implemented shortly. The battle groups were deployed to the Baltic States and Poland in early 2017. It should be noted that deployment of the battle groups and activation of NATO's integration units in each Baltic State since 2015 have increased NATO's capabilities to deploy more forces in these states as needed as well as strengthened synergies with the national forces ${ }^{3}$.

First of all, the achievements of NATO's strategic communication include positive attitude towards the battle groups in the host states. In the case of Lithuania, this also strengthened the trust in the Lithuanian Armed Forces. According to the population survey conducted by "Baltijos tyrimai" in April 2017, trust in the Lithuanian Armed Forces exceeded $70 \%$ again after a whi$\mathrm{le}^{4}$. In addition to this, $76 \%$ of the subjects completely agreed or agreed that NATO Enhanced Forward Presence Battle Group helped to defer hostile states.

This article analyses the communication actions of the North Atlantic Treaty Organization in order to reduce the potential risk of aggression against the Eastern Flank of the Alliance as well as assessment of the aforementioned actions. The objective of the article is to identify the role plaid by the elements of strategic communication in the deterrence process (and effectiveness thereof). This issue is analysed by referring to the case of NATO Enhanced Forward

\footnotetext{
${ }^{1}$ Weigel G., (2016), “The West's Debt to Lithuania/Lithuania’s Challenge to the West”, Lithuanian Annual Strategic Review, vol .14, p. 85.

${ }^{2}$ Robinson P. (2016), "Russia's role in the war in Donbass, and the threat to European security", European Politics and Society, 17:4, 506-521.

${ }^{3}$ Bodine-Baron E, Helmus T., Radin A., Treyger E. Countering Russian Social Media Influence. Santa Monica, Calif: RAND Corporation.

${ }^{4}$ Lietuvos Respublikos KAM (2019) , "NATO vertinimas Lietuvoje - aukščiausias per penkerius metus" [MoD of the Republic of Lithuania (2019), "NATO ratings in Lithuania - the highest in five years"], https://kam.lt/lt/naujienos_874/aktualijos_875/nato_vertinimas_lietuvoje_auksciausias_per_penkerius_ metus.html?c=1
} 
Presence in Lithuania. In order to answer the aforementioned question, the study focuses on the analysis aiming to identify the communication means and methods used by NATO Enhanced Forward Presence Battle Group in Lithuania, which are the most successful ones, as well as the challenges encountered in the process.

The study refers to the work by both classical deterrence strategy theorists, such as George, Grey ${ }^{5}$, Morgan ${ }^{6}$, and the fourth deterrence strategy theorists. The latter ones, including $\mathrm{Knopf}^{7}, \mathrm{Payne}^{8}$ and others, distinguished the tailored deterrence theory.

The conventional deterrence was analysed based on the publication by Gerson "Conventional Deterrence in the Second Nuclear Age". The deterrence model currently applied by the Baltic States is the subject of the research done by Veebel and Ploom. ${ }^{10}$ This is one of the first papers referring to deterrence in the Baltic Region following deployment of NATO Enhanced Forward Presence.

The objective of the presented study is to analyse how the stakeholders assess conformity of the strategic communication of NATO Enhanced Forward Presence in Lithuania with the communication objectives set out in the Alliance's official documents by assessing them in the context of the principle of deterrence.

The relevance of the research is determined by the aim to analyse how strategic communication helped in implementation of the principles of deterrence as well as to identify the place taken or potentially taken by strategic communication in respect of development of the deterrence policy. The research of this aspect has been scarce in the scientific field, especially in the context of the changed geopolitical realities in the region, which Lithuania is a part of.

\footnotetext{
${ }^{5}$ Gray C. (2008), “The definitions and assumptions of deterrence: Questions of theory and practice”, Journal of Strategic Studies, 13:4, 1-18.

${ }^{6}$ Morgan P. (2012), “The State of Deterrence in International Politics Today", Contemporary Security Policy, Vol. 33, No.1 p. 85-107.

${ }^{7}$ Knopf J. (2010), “The Fourth Wave in Deterrence Research”, Contemporary Security Policy, Vol. 31, No. 1 p. 1-33.

${ }^{8}$ Payne K. (2011), "Understanding Deterrence”, Comparative Strategy, 30:5, p. 393-427.

${ }^{9}$ Gerson M., (2009), "Conventional Deterrence in the Second Nuclear Age", Parameters: Journal of the US army war college, 39-3:18.

${ }^{10}$ Veebel V., Ploom I. (2018), “The Deterrence Credibility of NATO and the Readiness of the Baltic States to Employ the Deterrence Instruments”, Lithuanian Annual Strategic Review, vol. 16, p. 171-200.
} 


\section{The concept of deterrence and the correlation thereof with strategic communication}

\subsection{The principles of classical deterrence}

Classical deterrence theorist Morgan claims that deterrence is an old model of international relations. For example, the classical balance in the system of powers was based on deterrence, which was applied not only to prevent wars but during wars as well. In many different systems, such as the hegemonic system, an agreement between the major powers or a collective defence system designed to ensure and maintain security was based on deterrence: the powers used to form alliances or operated individually in order to demonstrate that a potential opponent faced the threat of dire consequences. In other words, deterrence was a normal standard practice, just like diplomacy or espionage, easily used in a comprehensive security strategy ${ }^{11}$.

The principles of deterrence were being widely developed during the $20^{\text {th }}$ century as well. It is worth mentioning the example of the situation during the Cold War, especially in the context of the existence of a nuclear weapon, when nuclear deterrence became the key part of the deterrence agenda of the major countries. Although absence of a conflict between major countries after World War II enabled claiming that deterrence worked, it failed to prevent minor conflicts or certain provocations and challenges.

Morgan claimed in the book "Deterrence Now" that "deterrence in international relations was generally understood as an attempt to prevent an enemy from attacking by demonstrating to that enemy that the latter would suffer irreparable damage in the event of an attack"12. In other words, prevention of a conflict is determined by the potential aggressor's understanding that it would not be able to win. However, this was not the only aspect of the classical deterrence theory, because generally the deterrence action is based on two pillars: assurance of deterrence by denying the opponent's chances of success (deterrence by denial) and by raising the fear of punishment (deterrence by punishment).

Deterrence by raising the fear of punishment gained popularity during the Cold War period. Large-scale nuclear armaments of the USA and the So-

\footnotetext{
${ }^{11}$ Morgan P. (2012), "The State of Deterrence in International Politics Today", Contemporary Security Policy, Vol. 33, No.1 p. 85-107.

${ }^{12}$ Morgan P. (2003). Deterrence Now, Cambridge University Press.
} 
viet Union led to the point when both countries and the blocs led by them, i.e., the members of NATO and the Warsaw Pact, were threatening each other with the possibility of striking them and causing irreparable damages. The development of the nuclear triad, i.e., the ability to strike from land, air, and water, was one of the key components of the deterrence by raising the fear of punishment.

The end of the Cold War and changes in the geopolitical situation brought some changes to the deterrence theory. The so-called "New Triad" consisting of nuclear and advanced conventional weapons emerged resulting in strengthened conventional deterrence theory. According to Gerson, "nuclear and advanced conventional weapons enabling to make a precise global strike demonstrate a growing belief that advanced conventional capabilities could replace nuclear weapons previously believed to be the only option"13.

We may claim that nowadays we are dealing with a changed projection of conventional deterrence: deterrence is no longer equated to creation of fear, but it is constructed through the threat of denying the adversary's ability to achieve one's goals ${ }^{14}$. Gerson claims that even deterrence remains a relevant task both in terms of the threat of a nuclear and a simple conventional conflict ${ }^{15}$.

The deployment NATO's allied forces in Lithuania (and other states in the region) per se is an action, which could be attributed to the paradigm of deterrence actions. However, the effectiveness of this action could depend on other aspects. Essentially, if any potential adversaries of NATO are looking for a quick and cheap victory, then the presence of the U.S. forces near the potential conflict region and the ability to deploy their forces quickly wherever needed, as demonstrated by the Alliance, guarantee for effective deterrence. However, if the attacking forces have a significant advantage over the defending forces, there is a high probability that deterrence would be ineffective and the potential adversary may resort to aggression in hopes of rapid success.

One of the elements of deterrence is reliability not only in the conventional sense, but in the broad one as well. When it comes to a nuclear weapon, as a tool of deterrence, the state planning on using one would always assess the high risk of retaliation / revenge, which would be the same: destructive, i.e., nuclear. In terms of reliability of the conventional deterrence, if the adversary sees the opposing forces and all integral parts thereof (political will, public support, etc.) as a reliable power, this would definitely affect one's final decision

\footnotetext{
${ }^{13}$ Gerson M., (2009) "Conventional Deterrence in the Second Nuclear Age", Parameters: Journal of the US army war college, 39-3:18.

${ }^{14}$ Ibidem, p. 33.

${ }^{15}$ Ibidem, p. 36.
} 
on (not) using force. However, if the aggressor believes that the likelihood of retaliation is low, then the benefits of aggressive actions outweigh the potential losses, and, respectively, deterrence is no longer effective.

Preventive escalation of a conflict is referred to as one of the available forms of deterrence. According to Mearsheimer, preventive escalation of a conflict could defer or stop adversaries, if they adhere to the provisions of aggressive realism believing that states must compete with each other for power, but they operate rationally, thus survival is their ultimate goal. However, such a strategy has its drawbacks, because the adversary could perceive escalation of a conflict as being provocative and hostile as well as requiring retaliation. From the point of view of the current analysis, this dilemma is best reflected in the situation where the military forces of the allies deployed to the Baltic Region in order to deter Russia (by applying the principle of deterrence by denial of an easy victory) could be perceived by Russia as being provocative and could result in conflict escalation ${ }^{16}$.

\subsection{Tailored deterrence}

One may have an impression that neither the classical deterrence nor the neorealistic extensive deterrence theories are sufficient means for a detailed description of the current situation, thus resulting in need to review the tailored deterrence theory as well. According to Knopf, formation of deterrence principles "requires bearing in mind the existing political regime and strategic culture of the state" ${ }^{17}$. The fourth-wave deterrence theorists also suggest analyzing information as another source of influence.

Payne distinguishes eight aspects of tailored deterrence that do not fit into the rational calculation units of the classical deterrence. Four out of eight aspects distinguished by Payne are used for the purposes of this study, taking into account NATO's communication objectives: psychological and cognitive aspects, ideology, culture, and geopolitics. The aforementioned aspects and the essence thereof are described in more detail in Table 1.

\footnotetext{
${ }^{16}$ Veebel V., Ploom I. (2018), op cit., p. 174.

${ }^{17}$ Knopf J. (2010), op.cit., p. 4.
} 
Table 1. Tailored deterrence ${ }^{18}$

\begin{tabular}{|l|l|}
\hline \multicolumn{1}{|c|}{ Aspect } & \multicolumn{1}{c|}{ Description of the aspect } \\
\hline Psychological, \\
cognitive aspects & $\begin{array}{l}\text { Individuals and groups often do not think and behave in a way predicted } \\
\text { by the theory of maximum benefit or the rational actor model. In terms } \\
\text { of deterrence, it is particularly relevant that leaders could take military, } \\
\text { aggressive measures as a result of incorrect assessment of the } \\
\text { adversary's powers, resources, intentions, or due to an error made within } \\
\text { the calculation process. Actors may also take greater risks in order to } \\
\text { maintain international positions, reputation, and local political support. } \\
\text { Decisions made in a group may not be optimum, or they could be } \\
\text { irrational. }\end{array}$ \\
\hline Ideology & $\begin{array}{l}\text { The whole of beliefs which the perception of the world is based on. } \\
\text { Ideology identifies the essential factors that determine certain behaviour, } \\
\text { helps to explain why certain things happen. Collective memory, elements } \\
\text { of the state apparatus embodying the state ideology at the institutional } \\
\text { level are important in this case. Ideological beliefs also define goals, their } \\
\text { hierarchy, and determination to implement the goals. These aspects are } \\
\text { important because they indicate the willingness to take the risks or to } \\
\text { make sacrifices for the sake of the goals being pursued. }\end{array}$ \\
\hline Culture & $\begin{array}{l}\text { Described as collective characteristics reflected in both private and } \\
\text { group behaviour. Culture helps to define the elements important in the } \\
\text { social environment, to associate with the value-based assessment, and } \\
\text { to identify the relation between "we" and "them". In terms of deterrence, } \\
\text { culture is important in order to identify other motives affecting the choice } \\
\text { of certain behaviour. Analysis of the culture helps to highlight social } \\
\text { values, the perception of honour, connections, and communication } \\
\text { structures, which are important for effective deterrence. }\end{array}$ \\
$\begin{array}{l}\text { The political, strategic importance of geography could affect the } \\
\text { determination to disregard deterrence measures. In this case the lack } \\
\text { of geographically extended deterrence - the problem of reliability, are } \\
\text { particularly important. }\end{array}$ \\
\hline Geopolitics
\end{tabular}

The identified criteria could enable us to analyse the aspects of deterrence subject to our interest in practice. They also provide a broader context for the deterrence-oriented communication. The aforementioned aspects are also relevant in terms of attempts in understanding whether deterrence could be achieved in one or another situation.

\subsection{The element of strategic communication in the context of deterrence}

Little has been said about the importance of strategic communication and its place in the context of deterrence so far. Only fourth-generation deterrence theorists suggest analysing information as a source of influence and highlight

\footnotetext{
${ }^{18}$ Payne K. (2011), op. cit, p. 401-412.
} 
the significance of strategic culture. It should be noted that the integration of strategic communication into deterrence has not been analysed on a broader academic level yet ${ }^{19}$.

We should start with the definition of strategic communication. NATO's documents describe strategic communication as follows: "Coordinated and appropriate use of NATO's communication activities and capabilities, including public diplomacy, public relations, military relations, information and psychological operations in support of the Alliance's policy, operations and activities in pursuit of NATO's objectives" ${ }^{20}$.

The U.S. Army Joint Staff defines strategic communication as "focussed United States Government efforts to understand and engage key audiences, also to create and strengthen conditions favourable for the advancement of the United States Government interests, policies, and objectives through the use of coordinated programs, plans, themes, products, and messages synchronized with the actions and instruments of national power"21.

We may also take into account the definition formulated by Tatham in his book. According to him, strategic communication is "systematic, continuous, and consistent activities carried out at a strategic, operational, and tactical level enabling to understand the target audience, to identify effective channels, and to develop and promote ideas through those channels as well as to encourage and to support a certain type of behaviour"22.

Looking at all of the presented definitions, it is easy to see that the purpose of strategic communication is specific objectives and the impact. For example, it refers to the impact on the audience, which can be perceived rather broadly (the audience may include other state leaders, decision-makers in the field of deterrence). In other words, the inclusion of the communication aspect into the formation of the deterrence principles is natural, thus strategic communication may be perceived as an appropriate tool for this purpose.

Tatham also presents the classical communication model in his book (see Figure 1), because it is an essential basis for any communication.

\footnotetext{
${ }^{19}$ There is only a few academic publications about this topic in Lithuania.

${ }^{20}$ NATO (2009), op.cit.

${ }^{21}$ Strategic Communication Joint Integrating Concept, 2017.

${ }^{22}$ Tatham S., (2008), Strategic Communication: A Primer. Defence Academy of the United Kingdom, p. 7.
} 


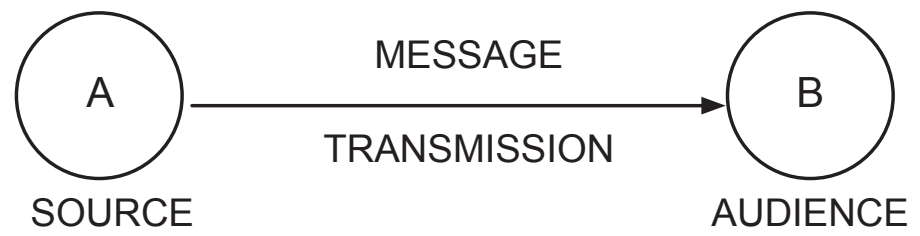

Figure 1. Basic communication model

However, the classical communication model is not sufficient for the strategic communication. Tatham claims that is reality the source and the audience interact under muvh more complex conditions and that their communication process is constantly affected by external factors. Taking this into account, he suggests an expanded and improved model (see Figure 2).

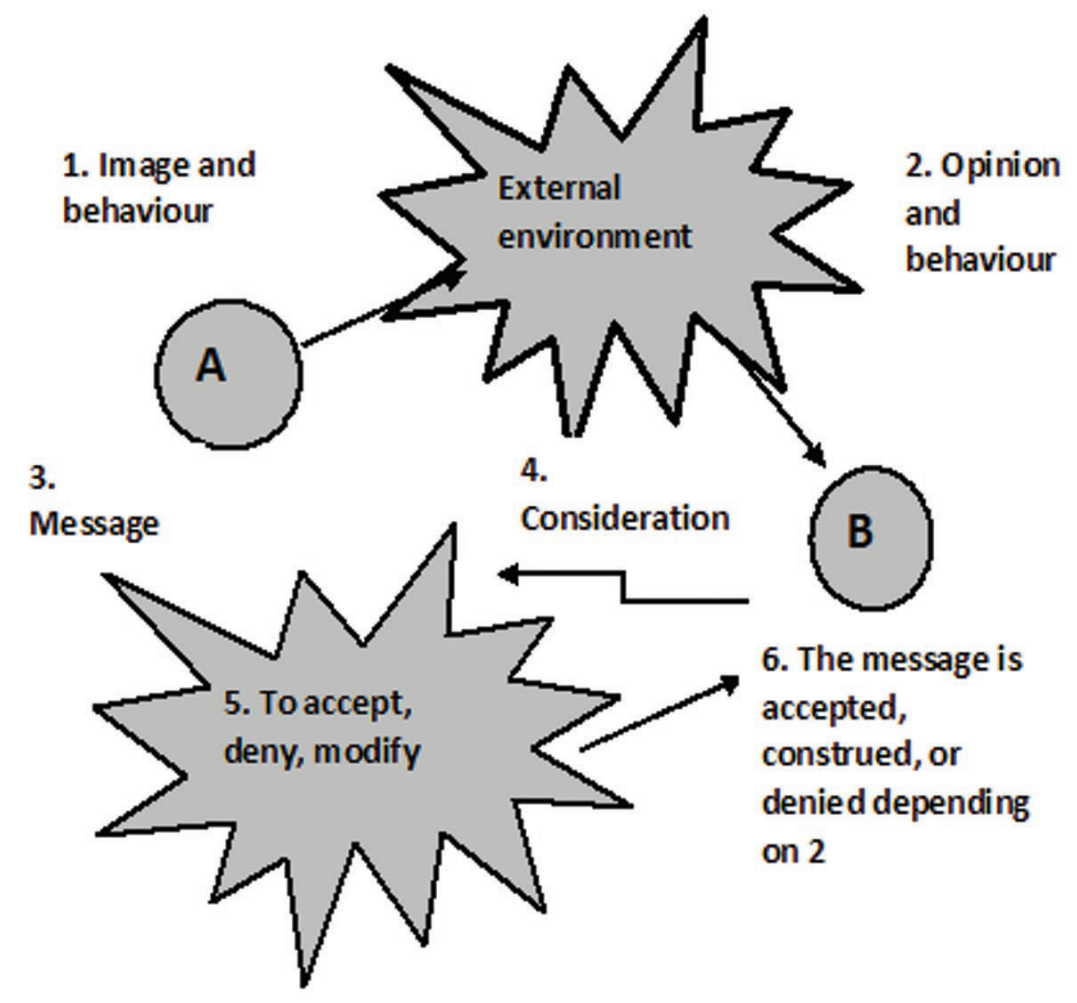

Figure 2. Communication model and external factors according to Tatham ${ }^{23}$

\footnotetext{
${ }^{23}$ Ibidem, p. 8.
} 
As this chart shows, the information communicated by source A and the effectiveness thereof on audience B will depend not only on the contents, form, and transmission channel of the message, but also on various types of factors: what is B's knowledge and opinion on A, how A's interests and identity are perceived, what are the values, ideas, and culture of $B$, whether they are compatible with those promoted by A and, in general, the environment where the communication process takes place, what other actors have an impact on the interaction of A and B, etc. Such an explanation of the communication model is important, because it can show an orientation towards tailored deterrence as well as distinguished psychological and cognitive aspects, culture, ideology, and geopolitics.

We should also take into account the activities of national authorities in charge of respective fields of communication when analysing communication of NATO Enhanced Forward Presence in Lithuania. The major communication of NATO Enhanced Forward Presence in Lithuania is carried out by the Strategic Communication Department of the Lithuanian Armed Forces. It is guided by the principles of Strategic Communication of the Lithuanian Armed Forces as defined in Section III of the Strategic Communication Concept of the Lithuanian Armed Forces:

Strategic communication of the Lithuanian Armed Forces shall mean coordinated and effective use of available information and communication tools and capabilities in pursuit of the goals of the Lithuanian Armed Forces. Strategic communication of the LAF shall ensure provision of information to the selected or assigned audiences regarding the objectives and intentions of the LAF in order to receive support for the LAF's actions as well as to deter and neutralize hostile intentions. The preventive objective of strategic communication of the LAF is to prevent emerging information threats, to strengthen critical thinking within the LAF, and to support the efforts made by the State of Lithuania in ensuring the resilience of the society and the LAF to hostile information influence aimed at undermining or otherwise affecting the Lithuanian state authorities and determination to defend the State of Lithuania. ${ }^{24}$

We can see that the presented concept followed by the Strategic Communication Department of the Lithuanian Armed Forces directly states that the audience shall be informed about actions aimed at "deterrence and neutralization of hostile intentions". In addition to this, the goals of strategic communication include the objective to strengthen the public's resilience to information-related threats, which are directly associated with the public's "determination to defend the State of Lithuania". As we have already mentioned, the latter aspect is also one of the essential elements of deterrence.

${ }^{24}$ Lithuanian Armed Forces Strategic Communications Concept 2018. 
In other words, the relation between the principles of strategic communication and deterrence is rather evident, thus enabling to substantiate the relevance of the following empirical research and the need for it.

\section{Assessment of the communication objectives of NATO Enhanced Forward Presence Battle Group deployed in Lithuania}

For the time being there are very few academic studies focussing on NATO Enhanced Forward Presence. This means that there are only a few texts available for reference in this phase of the attempts to reveal the selected topic. The paper by researcher Zapfe "Deterrence from the Ground up: Understanding NATO Enhanced Forward Presence" raises the following issue: "What is the political - military logic of NATO Enhanced Forward Presence in the Baltic States, taking into account the nature of the threats faced by the forces and what are the limits for non-nuclear deterrence?"25. First of all, it should be noted that the most important decision made in Warsaw during the NATO Summit held in July 2016 was permanent deployment of the Alliance's troops near the Russian border; this step would have been difficult to imagine prior to the events in Ukraine in 2014. This was noted by Respondent No. 3. He claimed that it was likely that deployment of NATO's forces was a big surprise for Russia. The Russian authorities probably thought that the decisions made during the Summit in Warsaw were merely empty declarations, but the Alliance's forces appeared in the Baltic States and Poland just a few months later.

Ringsmose and Rynning wrote in their paper "Now for the Hard Part: NATO's Strategic Adaptation to Russia"26 that the NATO Summit held in Warsaw in 2016 was the crowning factor finishing the entire adaptation process of the Alliance. NATO established a clear deterrence direction focussed on Russia by reviewing the strategy for deterrence by punishment. Naturally, the main focus was placed on the use of a nuclear weapon. The focus was on making sure that an attack would be unacceptable to the adversary and the cost would exceed the benefits expected to be achieved by the adversary. In addition to this, maintenance of NATO Very High Readiness Joint Task Force, VJTF, was

\footnotetext{
${ }^{25}$ Zapfe M. (2017), “Deterrence from the Ground up: Understanding NATO's Enhanced Forward Presence”, Survival, 59:3, p. 147.

${ }^{26}$ Ringsmose J. \& Rynning S. (2017), "Now for the Hard Part: NATO’s Strategic Adaptation to Russia", Survival, 59:3, 129-146.
} 
continued. Meanwhile, the eFP forces in the general context of deterrence also have their own role determined by the geographical location of the countries where they have been deployed to Ringsmose and Rynning noted: "The role of NATO Enhanced Forward Presence in the Baltic States is complicated. Multilateral units are separated by the Russian border $\mathrm{A} 2 / \mathrm{AD}$, therefore they play the main role as the classical tripwire"27. However, this article mostly focuses specifically on the communication activities of the eFP as a factor designed to strengthen deterrence.

\subsection{Strategic communication of NATO Enhanced Forward Presence Battle Group in Lithuania by using communication objectives}

Speaking of the Alliance's strategic communication is not that difficult because NATO carries out these activities purposefully by pursuing the formulated and set communication objectives. With regard to the eFP communication, the aforementioned objectives are as follows:

- to communicate the Alliance's political will, capabilities, and determination to defend and protect its citizens and territory in order to deter Russia;

- to communicate the Alliance's political will, capabilities, and determination to defend and protect its citizens and territory in order to gain and maintain the support of NATO Member States for the Alliance, by emphasizing reliability, focussing on cohesion of the Alliance and national resilience;

- to communicate understanding of the Alliance's continued need to protect its citizens in all Member States in order to gain and maintain the support of the Member States within the territory of the Alliance;

- to communicate consistently and reliably to avoid misunderstandings and miscalculations/ wrong assessments in relations with Russia in order to reduce and avoid unexpected escalations ${ }^{28}$.

It should be noted that each communication objective is divided into two or three information effects. The first communication objective, which is directly aimed at deterring Russia, is based on the following effects: 1) the Russian leadership acknowledges NATO's capabilities and willingness to defend

\footnotetext{
${ }^{27}$ Ibidem, p. 134.

${ }^{28}$ Joint Force Command Brunssum eFP FRAGO 019, (2019).
} 
each Member State from any aggression; and 2) different Russian audiences distinguish and perceive the size, objective, and possibilities of NATO Enhanced Forward Presence.

The second communication objective, which is aimed at securing support of the states hosting NATO Enhanced Forward Presence, is based on the following effects: 1 ) the eFP mission is widely supported by the public of the host states; 2) the public of the host states is confident that NATO would defend them from a conventional attack, 3 ) the public of the host states believes that the likelihood of the Russian aggression is now lower (following deployment of the eFP).

The third communication objective, which is aimed at maintaining the public support of the states sending their forces, is based on the following effects: 1) the public of the states sending their forces support deployment of their military units to the Eastern Flank of NATO; and 2) the states sending their forces support the idea of collective defence.

The fourth communication objective, which is aimed at preventing escalation, is based on the following effects: 1) the Russian leadership acknowledges the Alliance's activities as being defensive, 2) all elements of the host states acknowledge the defensive nature of NATO's activities ${ }^{29}$.

\subsection{Strategic communication of NATO Enhanced Forward Presence Battle Group in Lithuania (expert study)}

The presented expert study was conducted in order to explore several factors. It was sought to assess the realistic implementation of the four communication objectives as well as to analyse the reliability of communication and to determine the impact of communication on various specific segments of the audience in Russia and in Lithuania (the Russian elite: decision-makers; the ordinary Russian population/ the citizens of Russia; the Russian national community residing in Lithuania) in light of the applied deterrence theory. Given the natural limitation of the study, only the anticipated impact on the segments of the audience in Russia is discussed in this case.

The study was conducted by applying the semi-structured expert interview method. The interviews were conducted during the first quarter in 2019. The respondents were selected to include representatives of as many units involved in the process of strategic communication of NATO Enhanced

\footnotetext{
${ }^{29}$ Ibidem.
} 
Forward Presence as possible, thus enabling to conduct a more in-depth study. It involved 15 respondents representing different authorities ${ }^{30}$. Most of the representatives were interviewed in person, some of them were spoken to over the telephone.

\subsubsection{Evaluation of the first communication objective:} the Battle Group's communication reflecting the political will, capabilities, and determination to defend and to protect the citizens of NATO and the territory of the Alliance

The survey has shown that more than a half (60\%) of the respondents rated the implementation of the first identified objective (NATO communication by utilising the eFP Battle Group in Lithuania and communication of the eFP itself in Lithuania) as being good or very good. This indicates that communication aimed at deterring Russia was successful enough, despite the existence of certain challenges. It should be noted that $13 \%$ of the respondents rated communication with the lowest score possible, i.e., five points, which shows that they evaluated the communication as essentially being unsuccessful and, most importantly, not directed at deterring a potential enemy (the assessment results are shown in Figure 3).

The aforementioned significant difference in assessments could stem from some of the respondents' beliefs that communication was not targeted properly, that it was carried out superficially, without utilising and applying all measures needed to be taken resulting in resemblance to simple public relations rather than strategic communication. The negative aspects identified by the group of experts having rated communication as being inadequate would be discussed later in this paper.

\footnotetext{
${ }^{30}$ See Annex no 2.
} 


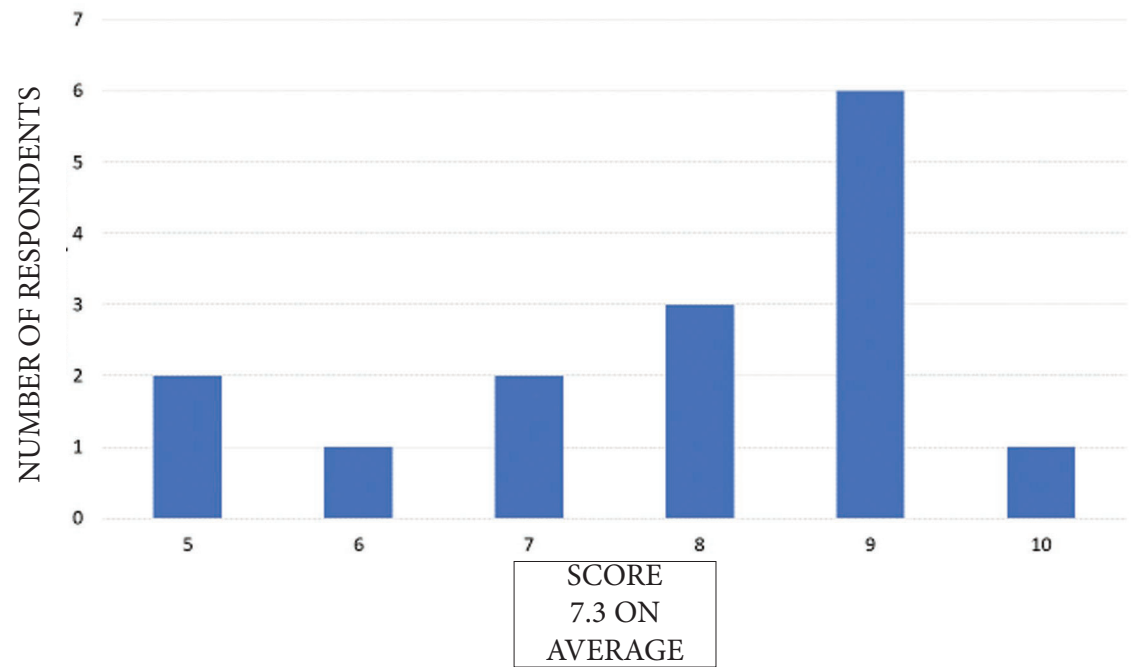

Figure 3. The first communication objective: communion of the political will, capabilities, and determination to defend and protect the citizens of NATO and the territory of the Alliance

In terms of deterrence itself, Respondent No. 10 suggests answering the question regarding handling of the term "deterrence" itself first. Does deterrence mean merely absence of potential enemy forces in the country or should successful deterrence mean noticeably reduced activity of enemy forces around the state borders: less provocative Air Force flights, fewer Navy ships passing in the vicinity of the territorial waters, etc.? This question is conceptual, thus, first of all, judging by the absence of enemy forces in the state, we may claim that deterrence works successfully. Respondent No. 13 claims that mere presence of NATO allied forces in Lithuania and other Baltic States was the best communication in itself. He identified a failure to prepare a specific eFP communication program prior to deployment of the forces as a key problem. Furthermore, no mass information campaign has been carried out concerning the matter of the eFP as it was done with the slogan \#WeAreNATO ${ }^{31}$.

As for deterrence itself and implementation thereof, one of the major identified problems was absence of clear communication channels enabling to reach the so-called Russian audience segments: the Russian elite, the Russian population, and Russian-speakers living in other states. The Russian information space is dominated by the media controlled by the Kremlin directly or

\footnotetext{
${ }^{31}$ \#WeAreNATO - An advertising campaign in order to increase NATO popularity within all NATO territory.
} 
through intermediaries resulting in dissemination of information favourable to the Kremlin as well as respective interpretation thereof. The respondents also noted that the eFP had no way of reaching segments of the Russian audience through the available channels, so this could be attempted at the general NATO level.

The respondents, who rated NATO communication with five points, named the factor that the scope of the Russian capabilities at the border with the Baltic States was not decreasing but rather growing as the main disadvantage of the communication being carried out. Naturally, this trend is a bad sign because it partially shows that NATO's measures were not as effective as we would like them to be. Nevertheless, Respondent No. 8 noted that, first and foremost, the main deterrence should be implemented at the political level, regardless that the scope of the conventional forces at the potential battlefield theatre was disproportionate. A clear political will and constant declaration of an uncompromising position as well as proper diplomatic work would enable to prevent escalation of a military conflict situation.

It is also worth mentioning the significant observation made by Respondent No. 4, namely that NATO Enhanced Forward Presence is fully integrated into the military forces of the host states. In the case of Lithuania, NATO Enhanced Forward Presence Battle Group was integrated into Mechanized Infantry Brigade "Iron Wolf", which would result in a completely different freedom of manoeuvre of Russia in the event of a conflict.

Respondent No. 3 noted, that he believed that Russia did take the situation seriously, which showed that the measures applied by the Alliance were working, otherwise Russia would not escalate this issue. On one hand, giving relevance to the topic of NATO "approaching the borders" favours the Kremlin's narrative of a "besieged fortress" 32 , but we should also keep in mind that the Russian culture sees demonstration of strength as means to earn some respect, therefore, NATO's determination to defend the Allies resonates in the public. With regard to the effectiveness of communication itself and the use of communication measures, the implementation of the first objective shows an aspiration to apply all measures identified in NATO's documents on strategic communication $^{33}$ : to increase messaging of the strong NATO Allies on collective defence; to communicate about the possibility to deploy more forces from the states sending their forces, if needed; to strive to maintain a large number of states sending their forces; to promote integration into local forces; and publication (see Figure 4).

\footnotetext{
${ }^{32}$ Kudors. A. (2016). "Near the Fortress: Ukraine's Echo in Political Relations between Russia and the Baltic States" in Kudors A., ed. (2016), Fortress Russia: Political, Economic, and Security Development in Russia Following the Annexation of Crimea and its Consequences for the Baltic States. Riga, p. 71-91.

${ }^{33}$ Joint Force Command Brunssum eFP FRAGO 019, (2019).
} 


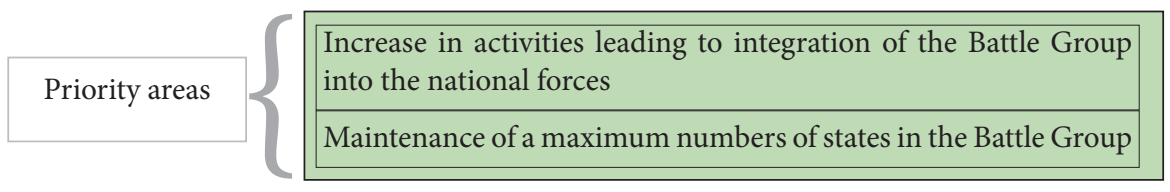

\begin{tabular}{|l|l|}
\hline $\begin{array}{l}\text { Other important } \\
\text { areas } \\
\text { on all of them }\end{array}$ & $\begin{array}{l}\text { Messages on social networks nothing that an attack on one (state) } \\
\text { means an attack on all of them }\end{array}$ \\
\hline $\begin{array}{l}\text { Member of official statements concerning the support for the de- } \\
\text { fence of the Baltic States }\end{array}$ \\
\hline $\begin{array}{l}\text { Messages on social networks concerning the support for the de- } \\
\text { fence of the Baltic States }\end{array}$ \\
\hline
\end{tabular}

Figure 4. Measures for implementation of the first objective

\subsubsection{Evaluation of the second communication objective: the Battle Group's communication aimed at gaining and maintaining the support of the host state and strengthening national resilience}

As the sixth figure shows (see Figure 5), none of the respondents rated this objective with the lowest score: five or six points. All scores ranged from seven upwards. It should be noted that one third of the respondents rated the second communication objective with a score of eight points. One fifth of the respondents evaluated communication regarding this matter as being excellent, i.e., by giving a maximum score. This evaluation is almost one point higher than the evaluation of the first communication objective. This essentially shows that the respondents evaluated the implementation of this communication objective better in comparison to evaluation of the first objective. 


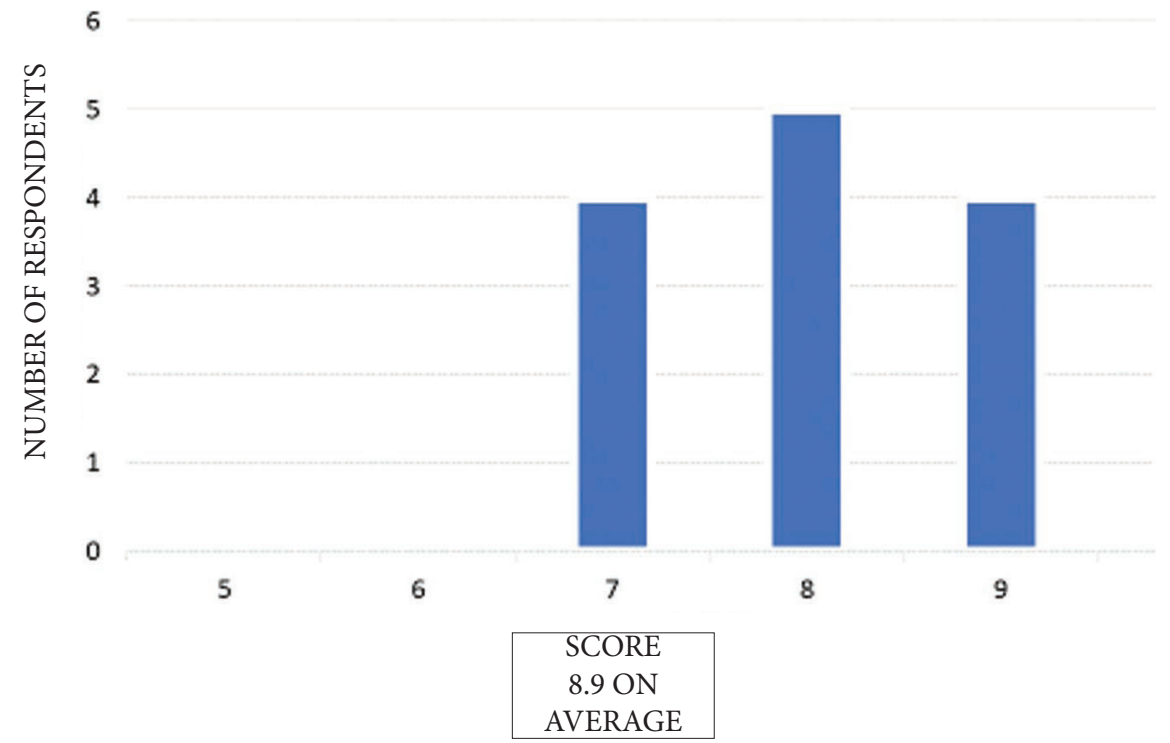

Figure 5. The second communication objective: to gain and maintain support of the host state and to strengthen national resilience

Several areas may be identified in respect of implementation of the objective: projects being implemented, information campaigns, integration into military units of the host state, readiness of the host state and the partner states to carry out and manage joint communications as well as overall popularity of NATO perceived by the public of the host state.

Analysis of the projects implemented by NATO Enhanced Forward Presence in Lithuania should include the arguments pointed out by Respondent No. 2 in regards to the significance of different types of projects, primarily to support the intention of the battle group leader. According to Respondent No. 2, most projects of NATO Enhanced Forward Presence are long-term, therefore they are inherently slow. Respondent No. 2 also noted that the second NATO communication objective did not address the issue of increasing public resilience, which should be done in order to gain even more public support. Respondent No. 2 also noted that one of the key objectives of social projects was to enable people to form their own opinion on NATO troops instead of relying on the messaging of the media outlets, which may include false news. In this case fake news would have a reduced impact on people's opinion regarding NATO Allies. Respondent No. 10 also noted the importance of such social projects as helping local residents by chopping firewood or lending a hand in other farm work, because they served to show local communities that soldiers 
not only trained during training exercises, but were also ready and willing to help the people around them.

Respondent No. 4 highlighted the importance of improving public awareness by providing information in the host state. He mentioned that the fourth rotation of NATO Enhanced Forward Presence also led to a clear three-phase information campaign. Each phase has different titles and objectives. The first phase is called "Ready for duty" and it is focussed on providing information on deployment of new units in the Battle Group. The second phase is called "Strong together" and it is focussed on the serving practices of the units in as well joint training exercises. The third phase "Together we serve" is focussed on communication concerning the outgoing units by showing that the service here, in Lithuania, did not end there and this NATO mission within the Alliance was much broader in nature than mere deployment of forces to the Eastern Flank of the Alliance. It should be noted that this three-phase communication concept was tested by the Belgian communication specialists within the context of the Air Policing Mission in Zokniai and it was later applied to the Battle Group where the troops of the Belgian Armed Forces serve as well.

Respondent No. 4 also highlighted the importance of integration into the national forces. He mentioned that smooth integration into Mechanized Infantry Brigade "Iron Wolf" helped in seeking the second communication objective, i.e., support of the local population. To some extent, the citizens of the state started perceiving the Battle Group as a part of the national forces, which helps improving the attitude of the host state's population in terms of belief that the Allies would defend our state, if needed. Respondent No. 5 noted that taking proper advantage of Lithuanian national holidays, when NATO troops participate in joint events with the Lithuanian society, also helped spreading information about NATO's tasks here, in Lithuania, more clearly and properly.

Respondent No. 12 noted that a clearer communication position of Lithuania, as the host state, was notably lacking at the very beginning, following the arrival of NATO Enhanced Forward Presence. There was no clear communication strategy, essentially, there was no proper preparation. There was no proper discussion among the authorities in charge for the NATO forces either. The communication plan for NATO Enhanced Forward Presence was prepared one year following the arrival of the forces, regardless that such documents should be prepared in advance. These aspects are also partially related to the critique expressed by Respondent No. 9, which is based on the statement that communication aimed at the Lithuanian society is implemented rather poorly, there is a lack of visual presentations, suitable information products, 
etc. Only individual initiatives of the states dominate in this area. The situation is slightly improved by the Battle Group's attempt to highlight the same goals as the ones identified by other NATO headquarters, such as the Headquarters Multinational Corps Northeast in Szcecin, the Allied Joint Force Command in Brunssum, etc., in their own communication messaging (this was noted by Respondent No. 6).

Respondent No. 13 emphasizes that NATO only needed to continue with what was being done prior to deployment of the forces, because the public support to NATO was high enough in this region while in Lithuania it was particularly high. For this reason the aforementioned Campaign \#WeAreNATO was implemented in Latvia, but not in Lithuania, because the surveys showed that the support for NATO was strong either way. Respondent No. 13 also noted it was very important that NATO accepted the narrative of the Baltic States involving the so-called "Forest Brothers" as its own narrative by creating video material on the post-war resistance. Therefore, it was no longer the story of Lithuania or Latvia only, but it was the story of the entire Alliance.

As Figure No. 6 shows, regardless that NATO implements all measures listed above, three of them can be identified as the dominant ones: retaining numerous forces of different states in the Battle Group; demonstration of the capability to support the Group by sending additional forces; strengthening the integration of the eFP into the forces of the host states.

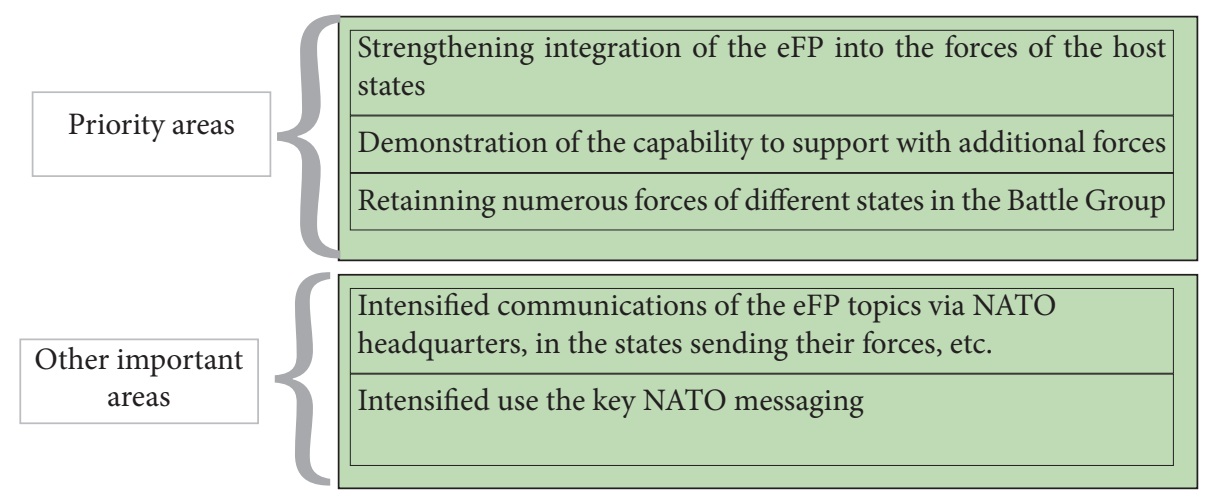

Figure 6. Measures for implementation of the second communication objective 
2.2.3. Evaluation of the third communication objective:

the Battle Group's communication aimed at gaining and maintaining support of the home audiences of the states sending their forces

The third communication objective is aimed at the audiences of the states sending their forces: decision-makers and ordinary citizens. Respondent No. 15 singled out the need to persistently disseminate information about the high necessity to receive support from foreign forces, which is constantly expressed by the representatives of the states sending their forces to the leaders of the host states (in our case: Lithuania). In this case it makes it easier for the politicians of the states sending their forces to justify deployment of their state troops to another country based on the request of the host state.

As we can see in Figure No. 7, none of the respondents rated implementation of this communication objective with the highest score, i.e., 10 points. This partly shows that the implementation of this objective was the most difficult one and the problems encountered in this regard were reflected by the reasoning offered by the respondents. Most of the respondents evaluated the effectiveness of this communication objective with a score ranging from 7 to 8 points: this was done by even $60 \%$ of the respondents. One fifth of the respondents evaluated the communication as being satisfactory by rating it with five or six points.

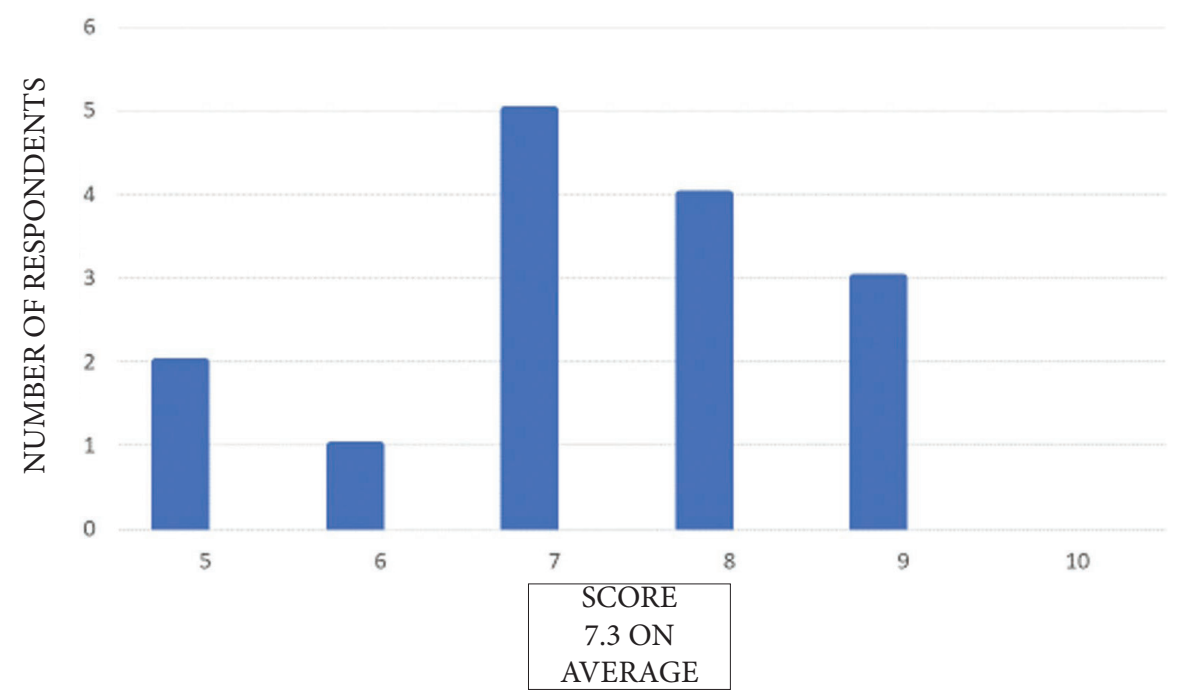

Figure 7. The third communication objective: to gain and maintain support of the states sending the forces 
Some of the respondents were truly very disappointed in communication presenting NATO Enhanced Forward Presence in their states. For example, Respondent No. 2 rated communication in his state with five points and identified many causes, which led to this situation. He started by stating that the perception of the sense of security itself in the Western Europe, in this case in the Netherlands, was different than in Lithuania and ended with the point that the majority of the Netherlanders did not see the point in having the state armed forces altogether. Naturally, this also complicates the communication support of the Enhanced Forward Presence. A similar point was also made by Respondent No. 13, who noted that the Western societies still fostered the belief developed after the Cold War that there would be no more wars, that there were no enemies, and that Russia was a partner that may be welcomed at the NATO headquarters. The thinking of some people has remained unchanged as well, they did not perceive Russia as a threat. Respondent No. 14 also gave low points when evaluating the implementation of the aforementioned communication objective. He singled out the key cause leading up to this, namely, poor German communication in disseminating information on forces deployed in Lithuania and the feature of the German strategic culture, i.e., the traditionally prevailing pacifism, which manifested itself as internal resistance to everything related to warfare. The society in Germany is essentially detached from military forces.

Respondent No. 3 shared his insight into the issue of mission popularity. According to him, it was difficult to understand why the mission of NATO Enhanced Forward Presence was relatively unpopular and did not receive as much attention as other NATO's missions, e.g., in Afghanistan. According to Respondent No. 3, this specifically applies to this mission, which is carried out in other NATO States and reflects the significance of NATO's existence. The Respondent also noted that historically Germany had a chance to recover after World War II specifically because the Allies were stationed on the German territory thus securing guarantees that West Germany would be able to live in peace and harmony. Now it was Germany's turn to return this tribute. Nevertheless, the Respondent also noted that the distinctive characteristics of Germany have led to the point where the state does not always follow the principles, which are universally acceptable in joint organizations, in this case it is NATO. For example, Germany does not follow NATO's guidelines for strategic communication, therefore the Battle Group led by Germany, being a subordinate of the NATO structures, finds itself at some deadlock: on one hand, it has been formed on the basis of the German Armed Forces and, first and foremost, 
follows the orders given by Bundeswehr Headquarters, but, on the other hand, the Battle Group is also a subordinate of Mechanized Infantry Brigade "Iron Wolf" under the Lithuanian Armed Forces and international staffs.

Most of the respondents noted that mere determination of the states to continue sending forces to Lithuania was a good sign showing that the partner states' approach remained unchanged regardless of relatively low visibility of the mission and popularity at the homes of the states sending their forces. They were determined to follow through their commitments. We can see this in Picture No. 8, which illustrates the measures for implementation of the objective.

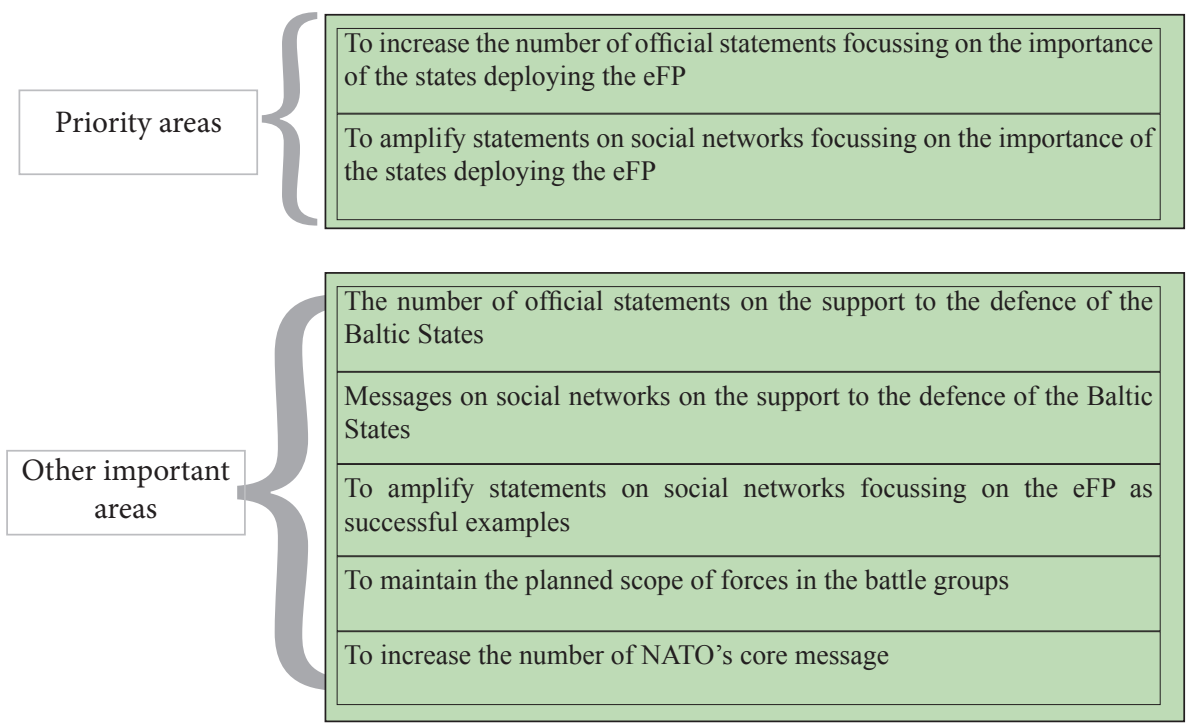

Figure 8. Measures for implementation of the third communication objective

As we have already mentioned, most of the respondents highlighted the need to amplify communications on the importance of the states deploying their forces and the need for the host state to receive such forces. Proper and active communication of the host state enable the public of the states sending their forces to see that their troops are welcome in those states and they help to counter the arguments of hostile propaganda that the states sending their forces behave aggressively and seek to "occupy" other states and to influence them in this way. In this case this is the main tool for implementation of this objective. 
2.2.4. Evaluation of the fourth communication objective: consistent communication of the Battle Group to avoid misunderstandings and miscalculations/ wrong assessments

The fourth communication objective is very similar to the first one and it also refers to deterrence of Russia. It is more focussed on the implementation of deterrence. It points to the need of having consistent and reliable communication enabling to avoid misunderstandings and miscalculations/ wrong assessments. It should be noted that communication is complicated by the changing Russian rhetoric. Back in 1999 Putin said that, first of all, solutions to the problems should be sought domestically within the state, but now the ideas spoken by him have completely changed ${ }^{34}$. According to Kolesnikov, researcher at Carnegie Moscow Centre, the offensive actions during the annexation of Crimea mobilized the Russian society. Life under "the conditions of a besieged fortress" began. Putin has ultimately become the symbol of the only leader capable of saving Russia and taking it back to its former glory ${ }^{35}$. Thus probably the most favourable communication out of the remaining options is to avoid provocative rhetoric as much as possible. All of the interviewed respondents rated the implementation of this objective with very high scores. There were no low scores, i.e., 5, 6, or even 7 points, at all. This indicates that in this case NATO's communication by utilising the Enhanced Forward Presence in Lithuania worked properly (see Figure 9).

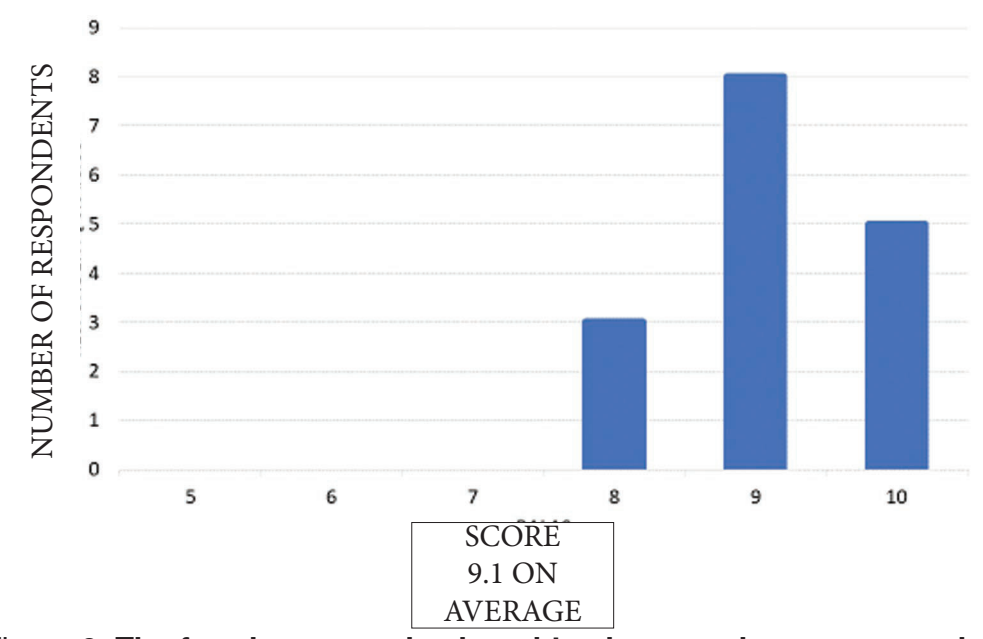

Figure 9. The fourth communication objective: consistent communication to avoid misunderstandings

\footnotetext{
${ }^{34}$ Kudors A., (2016), op.cit.

${ }^{35}$ Kolesnikov A., (2015). Russian Ideology After Crimea, Carnegie Moscow Center.
} 
Even a half of the participants in the survey rated the implementation of the fourth communication objective with 9 points and one third of them rated it with the highest score, i.e., 10 points. One fifth of the respondents evaluated the communication as being good and gave 8 points. The main arguments in favour of such a positive evaluation of the communication were the fact that the eFP actually communicated in a proper and non-aggressive manner, the communication was not provocative thanks to the avoidance of ambiguous messages. The overall assessment is 9.1 points.

Nevertheless, some criticism was expressed as well. According to Respondent No. 2, the eFP communication lacked certain consistency resulting from frequent rotation of the battle group staff. This Respondent also noted that often communication was limited to dissemination of information in the so-called bubble when all messages stayed within the boundaries of the information space of NATO and the European Union. Respondent No. 2 also noted that various projects involving the civilians and their education was the best way to avoid misunderstandings and misconstructions regarding the actions.

However, there are some limits to knowledge when it comes to proper assessment of the fourth communication objective. There are not enough proper means enabling to assess how NATO is perceived by the so-called Russian audiences resulting from the use of communication by the Battle Group. According to Respondent No. 3, if Russia was not deterred, then the Russian media would have no point in talking about NATO so much or to focus on it to such a great extent. The deployment of the forces could have been a big surprise for Russia, because the decision to deploy forces made during the NATO Summit held in Warsaw in July 2016 could still have been seen as a declarative statement, but this decision was implemented already in 2017.

Respondent No. 4 noted that the eFP Battle Group in Lithuania only served as a warning. Russia is perfectly aware that the presence of the forces here is limited, but it also understands that it would be met by the representatives of the armed forces of 7 states as soon as its troops cross the border. Respondent No. 5 emphasized that the eFP communicated properly, the messages were formulated in the defensive format. The purpose of this format is to support the sovereignty of Lithuania. Respondent No. 6 noted that the eFP communication was mostly focussed on the logistics capabilities of the eFP, which also showed that the eFP communication was not of an aggressive type.

Respondent No. 10 emphasized that, from the tactical point of view, the entirety of the eFP communication was very significant, because the political weight of eFP capabilities was much higher in comparison to Russia despite 
of their smaller scope. Respondent No. 12 noted that all eFP messages were formulated properly, they supported NATO's communication line, however, everything was viewed negatively in Russia regardless what NATO or the eFP were doing.

Depending on which means were the most effective (see Figure 10), none of the interlocutors mentioned the messages on NATO Enhanced Forward Presence Battle Group communicated by their state leaders during the meetings with the representatives of the Russian Government. Communication on the eFP is often left to the discretion of the Secretary General of NATO as well as other high-ranking NATO officials.

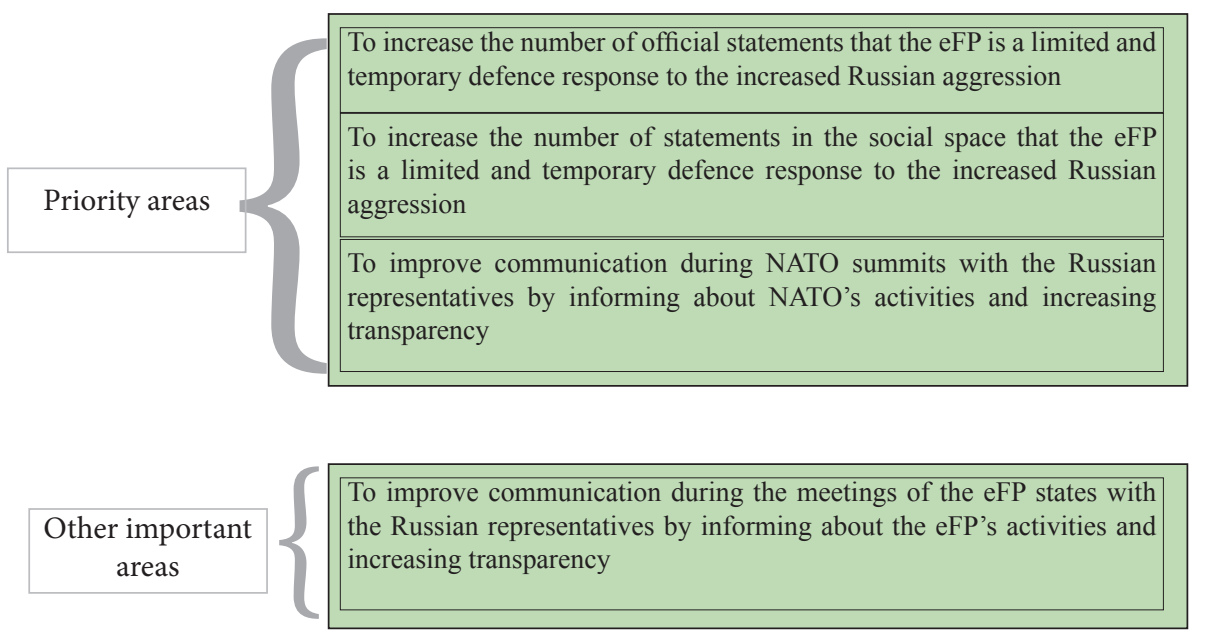

Figure 10. Measures for implementation of the fourth objective

A review of all communication objectives and means for their implementation shows that the fourth communication objective and implementation thereof were rated as the best ones. All respondents had the opinion that the eFP truly did not communicate aggressively or provocatively, the communication was consistent and reliable. There is a slight lack of clearer identification of means designed for implementation of communication by the respondents.

\subsection{Suggestions for improving communication}

The conducted study enables seeing certain gaps in the eFP communication and considering options for amplification of respective communication functions. In light of the assessment of the implementation of the 
strategic communication objectives of NATO Enhanced Forward Presence Battle Group, we may present the following suggestions for improvement of communication, which are mainly focussed on better fulfilment of NATO's communication objectives.

Table 2. Recommended communication model

\begin{tabular}{|l|l|l|}
\hline \multicolumn{1}{|c|}{ Objective } & $\begin{array}{l}\text { Situation in the Battle } \\
\text { Group }\end{array}$ & \multicolumn{1}{c|}{ Recommendations } \\
\hline $\begin{array}{l}\text { The first } \\
\text { communication } \\
\text { objective }\end{array}$ & $\begin{array}{l}\text { There are no } \\
\text { possibilities for } \\
\text { communication with the } \\
\text { Russian audiences. }\end{array}$ & $\begin{array}{l}\text { To communicate messages in multiple } \\
\text { languages when communicating via their } \\
\text { channels. }\end{array}$ \\
\hline $\begin{array}{l}\text { The second } \\
\text { communication } \\
\text { objective }\end{array}$ & $\begin{array}{l}\text { Social projects do not } \\
\text { always have continuity. }\end{array}$ & $\begin{array}{l}\text { 1) To prepare communication plans } \\
\text { at various levels clearly detailing } \\
\text { responsibilities for different types of } \\
\text { activities involving the public; } \\
\text { 2) To amplify the mutual integration of } \\
\text { the Enhanced Forward Presence and the } \\
\text { Lithuanian Armed Forces through various } \\
\text { events and training exercises; } \\
\text { 3) To initiate establishment of } \\
\text { communication positions in staffs at } \\
\text { different levels. }\end{array}$ \\
\hline $\begin{array}{l}\text { The third } \\
\text { communication } \\
\text { objective }\end{array}$ & $\begin{array}{l}\text { Poor communication } \\
\text { for home audiences. }\end{array}$ & $\begin{array}{l}\text { 1) To seek keeping the issue of the Battle } \\
\text { Group in the agendas of the politicians of } \\
\text { the host state; } \\
\text { 2) To clearly communicate the need } \\
\text { for the Enhanced Forward Presence } \\
\text { to the officials of different ranks in the } \\
\text { host state during the visits paid by the } \\
\text { representatives of the states sending } \\
\text { their forces. }\end{array}$ \\
\hline $\begin{array}{l}\text { The fourth } \\
\text { communication } \\
\text { objective }\end{array}$ & Proper communication. & $\begin{array}{l}\text { To maintain consistent, transparent, } \\
\text { timely, and accurate communication. }\end{array}$ \\
\hline
\end{tabular}

\section{Conclusions}

Different deterrence models provide a better understanding of NATO's efforts to prevent Russia's aggressive policy in the close neighbourhood. Strategic communication plays a very important role in the process of deterrence of Russia. However, the classical deterrence model does not analyse the factor of application and taking advantage of communication in the deterrence process. It is discussed in more detail in the tailored deterrence theory as the representatives thereof claim that information must be analysed as another source 
of influence. The representatives of the school of tailored deterrence identify several specific aspects to be addressed in order to influence a potential adversary. Unfortunately, no representatives of the aforementioned schools of deterrence cover the topic of the importance of encouraging the citizens of the host state, which is a desirable element of deterrence of an adversary in the modern warfare. For this reason it would be advisable to include assessment of this situation as well as the impact and significance of the available defence capabilities to the audiences of the host states in future papers based on this deterrence theory.

Changes in the geopolitical situation at the eastern border of NATO resulting from the aggressive actions of Russia in Crimea and in East Ukraine forced the Alliance to respond quickly, but adequately. The decision to establish NATO Response Force was approved during the NATO Summit held in Wales in 2014 leading up to another step, which was taken in Warsaw in 2016 when it was decided to deploy the NATO Enhanced Forward Presence Battle Groups to the Baltic States and Poland in addition to initiation of tailored presence in the Black Sea Region: in Romania and Bulgaria. These decisions shaped the new deterrence policy directed at Russia while strategic communication was applied in order to facilitate implementation thereof. NATO focussed on proper communication on actions being implemented aiming for maximum deterrence of Russia. Within the course targeted communication, the Allied Joint Force Command in Brunssum has formulated four communication objectives, which are being implemented by involving NATO Enhanced Forward Presence Battle Groups in the Baltic States and Poland as well as by using other civil / military instruments.

The conducted empirical analysis of the case has shown that the representatives of the parties involved in the process evaluated the communication of NATO Enhanced Forward Presence Battle Groups in Lithuania as fairly effective and as having found its niche in the common strategic communication agenda of NATO successfully enough, although there were some drawbacks as well. It should be noted that the representatives of the parties involved in the process are rather closely involved in the day-to-day means for implementation of NATO's strategic communication, therefore their assessments may be impartial and subjective. On the other hand, their direct work in the field of strategic communication enables them to professionally identify and name the problems and shortcomings faced by them. This enables seeing the existing problems more clearly and suggesting more effective ways to solve them.

It should be noted that in this case even two out of four NATO communication objectives are directly aimed at deterring Russia; nevertheless, 
based on the assessment of the stakeholders in Lithuania, it is rather difficult to achieve them due to a lack of access to appropriate channels in the Russian media and inability to evaluate the effectiveness of the communication efforts being made. The third communication objective, i.e., forming an appropriate opinion in regards to the Enhanced Forward Presence in the states sending their units, is also fulfilled poorly. The low level of awareness in respect of the Enhanced Forward Presence in these states is also affected by the citizens' overall lack of interest in security topics. It is sought to take better advantage of the visits of high-ranking foreign guests in Lithuania as much as possible for the purpose of implementation of the third communication objective. One of the main purposes of such visits often includes visiting the Enhanced Forward Presence in Rukla as well. The stakeholders pointed out that currently the communication of the Battle Group in Lithuania is mostly focussed on the second communication objective of NATO, namely, work focussed on different audience segments of the host state, i.e., Lithuania. This is expressed in the form of implementation of various social projects (together with the Lithuanian Armed Forces and independently), visits to schools, demonstration of military equipment and armament in cities and towns during training exercises, active participation in events dedicated to celebration of Lithuanian national holidays.

Upon assessment of the aforementioned factors, we may state that the present-day communication of NATO Enhanced Forward Presence Battle Group in Lithuania is mostly focussed on encouraging the citizens of the host state. Based on the criteria set out in the tailored deterrence theory, we may state that currently NATO has no adequate means designed to have a significant effect on the target audience segments in Russia. Despite that Russia remains deterred in the near future, failure in the implementation of the aforementioned objectives in the long run could have a negative impact in the overall deterrence context.

July 2020 
Honourable Expert,

I kindly ask you to answer the following questions. Anonymity of your answers is guaranteed, so I hope you would answer the questions in detail.

Name, surname

Rank

Country

Specialization

How is your work related to the eFP?

How long have you been working with the eFP?

The first four questions will be related to NATO Stratcom objectives. Please rate NATO's communication on a scale from 5 to 10: 5 means that the effectiveness of communication is middling and 10 means that you evaluate it as being perfect.

1. Please evaluate how successfully NATO has been using NATO eFP BG Lithuania for communication of political will, capability, and resolve to defend and protect the citizens of the Alliance and the territory in order to contribute to deterring Russia over the past 2 years. Please name the measures which work best.

\begin{tabular}{|l|l|l|l|l|l|}
\hline 5 & 6 & 7 & 8 & 9 & 10 \\
\hline
\end{tabular}

2. Please evaluate how successfully NATO has been using NATO eFP BG Lithuania for communication of the Alliance's political will, capability, and resolve to defend and protect its citizens in order to gain and maintain NATO Members' support to the Alliance, with a focus on assurance, cohesion, and national resilience over the past 2 years. Please name the measures which work best.

\begin{tabular}{|l|l|l|l|l|l|}
\hline 5 & 6 & 7 & 8 & 9 & 10 \\
\hline
\end{tabular}

3. Please evaluate how the use of NATO eFP BG Lithuania by NATO communicates an understanding of the continuing need of the Alliance to defend its citizens in all Member States to gain and maintain the Members' support 
for the Alliance throughout its territory over the past 2 years. Please name the measures which work best.

\begin{tabular}{|l|l|l|l|l|l|}
\hline 5 & 6 & 7 & 8 & 9 & 10 \\
\hline
\end{tabular}

4. Does NATO use the eFP BG Lithuania communication in a coherent, credible, and consistent manner in order to avoid misunderstandings and miscalculations in relation with Russia, and thereby contribute to risk reduction and avoiding unintended escalation and in what way? Please name the measures which work best.

\begin{tabular}{|l|l|l|l|l|l|}
\hline 5 & 6 & 7 & 8 & 9 & 10 \\
\hline
\end{tabular}

5. How the communication of NATO eFP BG Lithuania contributes to positive and credible enhancement of NATO eFP BG image?

6. How the use of the eFP BG communication by NATO contributes to the narrative/ discourse driven by the Russian political leaders: "Besieged fortress surrounded by external enemies", "The West is morally rotten" "Russian way as an alternative to international relations". Rate on a scale from 1 to 5: 1 means that the narrative is not strengthened, 5 means that it is highly strengthened.

Narrative No. 1 "Besieged fortress surrounded by external enemies"

\begin{tabular}{|l|l|l|l|l|}
\hline 1 & 2 & 3 & 4 & 5 \\
\hline Narrative No. 2 “The West is morally rotten” & 5 \\
\hline 1 & 2 & 3 & 4 & 5 \\
\hline Narrative No. 3 "Russian way as an alternative to international relations" \\
\hline 1 & 2 & 3 & 4 & 5 \\
\hline
\end{tabular}

\section{Annex No. 2. List of the respondents}

1. Respondent No. 1: Representative of Iceland at NATO Enhanced Forward Presence in Lithuania.

2. Respondent No. 2: Representative of Netherlands at NATO Enhanced Forward Presence in Lithuania.

3. Respondent No. 3: Representative of Germany at NATO Enhanced Forward Presence in Lithuania.

4. Respondent No. 4: Representative of the German Representation Group in Lithuania.

5. Respondent No. 5: Representative of NATO Force Integration Unit in Lithuania. 
6. Respondent No. 6: Representative of the Czech Republic at NATO Enhanced Forward Presence in Lithuania.

7. Respondent No. 7: Representative of Belgium at NATO Enhanced Forward Presence in Lithuania.

8. Respondent No. 8: Representative of Belgium at NATO Enhanced Forward Presence in Lithuania.

9. Respondent No. 9: Lithuanian journalist writing on topics of NATO Enhanced Forward Presence in Lithuania.

10. Respondent No. 10: Representative of NATO Strategic Communications Centre of Excellence in Riga.

11. Respondent No. 11: Representative of the Ministry of National Defence of Lithuania.

12. Respondent No. 12: Representative of NATO Force Integration Unit in Lithuania.

13. Respondent No. 13: Representative of NATO Public Diplomacy Division.

14. Respondent No. 14: Employee of the Lithuanian Embassy in Germany.

15. Respondent No. 15: Representative of the Ministry of Foreign Affairs of Lithuania. 